\title{
Research on Practice of Maker Pedagogy Supported by Educational APPs
}

\author{
Zhuang Li \\ School of Network and Communications of Changzhou College of Information Technology, Jiangsu, \\ Changzhou, 213164 China
}

Keywords: Maker pedagogy; educational APPs; practical research

\begin{abstract}
In the present general context of the rapid development of Internet, education also joins in the Internet, and enters the era of innovation-oriented Internet education. In particular, the ideological trend of innovative education is initiated mainly by maker campaign, and a new educational method adapting to it emerges. The maker pedagogy is centered on people, encourages independent learning, innovative learning and cooperative learning by students, and mainly cultivates students' innovative thinking and practical spirit. Furthermore, mobile education resources represented by APPs are also increasingly more abundant, and can meet the needs of college students in various aspects. Smart APPs have very strong interactivity, provide great supports for maker pedagogy in terms of content and technology, and become a new choice for more and more college students in their learning and life. This paper further researches maker pedagogy and some educational APPs based on information extension class of educational APPs, with reference to maker pedagogy at home and abroad and experience in educational APPs, using a series of scientific research and investigation methods.
\end{abstract}

\section{Introduction}

In the 21st century, rapid development of the Internet and multimedia technology has a great influence on people's life and learning, and greatly changes people's thinking and learning methods. In this general context, the general trend of maker campaign is sweeping the world, and represents progress and innovation based on the concept of sharing, communication, design and innovation. Rapid development of the maker campaign also promotes reform of the educational mode. The maker campaign changes student learning style and the previous rigid exam-oriented pedagogy. Furthermore, it can emancipate students' natural instincts, and encourage united, cooperative, independent and innovative learning modes. Maker pedagogy guides student learning using a new digital technology, and forms a whole new student-centered learning mode, greatly increases students' enthusiasm for learning, and improves the teaching level and educational quality. Therefore, rise of the maker campaign is a new technology following the trend of the times, can renovate the original educational method, and complies with the teaching mode for cultivating talents in the current era.

\section{Research background of maker pedagogy APP}

As is known to all, now the compulsory courses and elective courses are set in colleges and universities to improve professional quality and other qualities of students, and mainly cultivate independent learning ability and innovative consciousness of students. However, in terms of the present situation, courses are in a single form in colleges and universities, teachers infuse knowledge, and students just mechanically accept knowledge with less interaction between students and teachers. With the dull and single teaching mode, teaching is dull, and can neither cultivate diversified talents, nor stimulate student learning interests. Moreover, if teachers neither have skilled teaching levels, nor can teach students according to students' aptitude, then the teachers cannot meet various needs of students. In the traditional teaching mode in colleges and universities, the class time is short, teachers usually reduce class time in order to catch up with the schedule, but don't have enough time to tutor students for some uncommon problems provided by students, 
thereby failing to help students to learn knowledge and improve their ability. There is a lack of good interaction between teachers and students, so teachers cannot effectively guide and help student learning activities. Therefore, such a learning method cannot be accepted by students, resulting in a lack of effective communication and exchange between teachers and students, and cold emotions between teachers and students. College teaching curriculum contents are too academic and professional to achieve vivid teaching, so that students can neither learn real knowledge, nor apply knowledge to practice, which is also difficult to provide a lot of help in the future work. Moreover, the courses in colleges and universities are professional with dispersed contents. In class, most students play with their mobile phones, and are difficult to learn real knowledge. This situation will form a vicious circle, so that students become bored with specialized courses. At present, the network teaching environment is gradually perfect, new educational ideas constantly emerge, and the maker campaign emerges in response to the proper time and conditions, so that science, technology and education are perfectly combined, and the new educational ideas are acknowledged by colleges and universities.

\section{Application status of educational APPs}

Mobile communication network is developing rapidly, smart phones and tablet computers become indispensable learning tools for people in daily life, and educational APPs have been widely used, so that students' life style has fundamentally changed. Educational APPs can integrate knowledge and various resources, can present knowledge in a variety of forms, such as texts, videos, images and animations, effectively improves student learning interests, and provides students with a good learning platform and communication platform. As can be concluded through various investigations and researches, educational APPs can be divided into many categories, specifically including: reading APPs, reference book APPs, game APPs, early education APPs, reminder APPs, examination APPs and communication APPs. These APPs not only enable students to learn anytime and anywhere, easily review and improve the learning efficiency, but also can communicate with classmates in real time, and discuss with other students, so as to solve problems.

However, these educational APPs still have some problems, and students are addicted to mobile devices in class, thereby influencing their attentions. At the same time, these APPs cannot achieve quantitative evaluation, and need to be further evaluated scientifically. Therefore, the authenticity of some APPs remains to be considered. However, these educational APPs have many useful advantages, despite of these disadvantages. Mobile devices are small, beautiful, and easy to carry with strong practicability. Nowadays, mobile devices have gradually become the learning style selected by people, especially college students. Educational APPs can stimulate student learning interests, help teachers' teaching activities, enhance students' interaction with teachers and students, form a good learning environment, and improve learning efficiency.

\section{Reform of integrating teaching activities and technologies in colleges and universities}

The traditional learning modes are teacher-centered, the emerging network learning mode is student-centered, and the existing mobile learning mode is an informal learning, i.e., just-in-time learning. Since 2010, most famous universities in the world have applied campus APPs, and whereafter other universities in the world have successively followed them, thereby further deepening the theory integrating information technology and curricula. Various colleges and universities in China also successively develop educational APPs, and gradually put the APPs into practice, so that all teachers and students in colleges and universities can download relevant learning materials using mobile devices, have access to the school library, read books and view school notices. From the perspective of students, college students need a lot of professional knowledge. But in this society of fast era, students do not have enough time, and fail to achieve required professional knowledge on some platforms. The advent of educational APPs enables students to study anytime and anywhere, such as in subway, on a bus, in classroom and in dormitory, and to make full use of spare time and odd time. Now, the post-90s college students are in the 
majority, are able to flexibly use network technology and a variety of APPs. What is most important is that students are not interested in traditional learning methods, and are willing to accept new media and new educational methods.

From the perspective of educational APPs, APP development threshold is low, and research and development of educational APPs is highly feasible in colleges and universities. Therefore, it is very feasible to make up for the deficiency of traditional pedagogies using educational APPs. Meanwhile, this is also the inevitable trend of era development. Small mobile devices play a huge role in the development of educational APPs.

\section{Practical application and development of maker pedagogy}

Maker is a physical space designed to provide a development space for information technologists, scholars, and people who love computer technologies. Like-minded people can communicate with each other in the maker to invent various electronic products and develop high-tech products.

With the continuous development and application of maker space, more and more scholars begin to research this new technology. Maker pays attention to student-centered educational ideas, provides students with a good platform for learning and communication, can fully mobilize students' enthusiasm for learning, and stimulates their creativity. Maker pedagogy encourages students to actively learn in the process of exploration and invention, emphasizes conversion between teaching and learning styles, and believes that creation is learning. In the maker pedagogy, students can choose the learning contents based on their own interests, while teachers can encourage students to make innovations by means of education, and cultivate students' creativity and imagination. In conclusion, maker pedagogy can promote students' enthusiasm for learning, so that students can acquire more knowledge using new technology, and apply the knowledge to practice.

\section{Conclusion}

In conclusion, the educational modes of educational APPs are more efficient than the traditional educational modes, enable students to better master knowledge, and further enable students to flexibly master learning methods and learning strategies. In terms of students' satisfaction, educational APPs can further satisfy students' demands for diversified knowledge, and can further stimulate students' enthusiasm for learning. In terms of interaction between teachers and students, the educational modes of educational APPs can achieve more frequent interaction between teachers and students and more active class atmosphere than traditional pedagogies. On the whole, educational APPs play a good role in promoting student learning, and play a role in inspiring education and teaching in colleges and universities. The learning concepts of educational APPs are integrated into teaching in colleges and universities to enrich informatized education resources, thus improving the teaching effect in colleges and universities. Traditional textbooks are perfectly combined with educational APPs to jointly promote student learning.

\section{Acknowledgements}

Program: 2016 scientific research program number: CXRS2016003 of natural science and School of Humanities and Social Sciences title: Research on Practice of Maker Pedagogy Supported by Educational APPs Zhuang Li General program

\section{References}

[1] Yan Huanhuan \& Liu Yanhua. Design and Development of Mobile Learning Platform in Colleges and Universities of Common Required Courses based on Mobile Internet Technology [J]. Primary and Middle School Educational Technology, 2015 (5): 75-78.

[2] Zhou Yan. Practice of Flipped Class Teaching Mode Based on Mobile Apps [J]. Suzhou 
Education Informatization, 2016 (3): 41-43.

[3] He Kekang. Learn the "Ten-Year Development Plan of Education Informationization"Interpretation of "Deep Integration between Information Technology and Education" [J]. China Educational Technology, 2012 (12): 19-23.

[4] Tian Jianlin. Experimental Study on Effectiveness of Integration of Information Technology in Classroom Teaching [D]. Dalian: Liaoning Normal University, 2012 (04): 19-20. 